\title{
Online Monitoring Solutions of Efficiency for Automotive EGR Heat Exchangers
}

\author{
Bianca Maria Vaglieco ${ }^{1}$, Simona Silvia Merola ${ }^{1, *}$, Adrian Irimescu ${ }^{1}$, Vasco Zollo ${ }^{2}$, Raffaele De Marinis ${ }^{2}$ \\ ${ }^{1}$ Istituto Motori - CNR , Via G. Marconi 4, 80125 Napoli, Italy \\ ${ }^{2}$ Demax SRL, Boscofangone ASI NOLA, 80035 Nola, Italy
}

\begin{abstract}
Internal combustion engines are the dominating technology in the automotive transport sector. Within this context, even incremental improvements in efficiency are essential for reducing overall environmental impact. Maintaining rated specifications is also an important issue, with monitoring solutions being more and more the focus of development. Cooled exhaust gas recirculation (EGR) is a well established technology that allows improvements in efficiency and reduction of emissions. The present work looks at different solutions focused on the integration of a digital sensor directly into EGR valves, thus ensuring continuous monitoring and extensive diagnostics. As an initial stage, an evaluation of gas cooling efficiency was performed and different routes were identified to allow this parameter to be monitored online. Measurement of flow was discarded as a solution, mainly due to cost issues and complications of its application. Temperature based evaluation of efficiency was found to ensure the best compromise, with acceptable accuracy and practically no integration difficulties. This initial evaluation allowed the definition of basic principles of operation for the sensor, so as to ensure the final goal of more efficient and longerlasting EGR modules through continuous performance monitoring.
\end{abstract}

\section{Introduction}

Internal combustion engines are still the technology of choice for the automotive industry [1] and are set to feature continuous improvement in the near and midterm future [2].

Compression ignition (CI) units deliver high fuel conversion efficiency and can ensure reduced environmental impact even with flexible fuel operation [3]. Their adaptability to alternative combustion modes can provide further enhancement of efficiency and emission characteristics [4], while continuous improvement of different components [5] ensures reliable operation in a wide range of conditions.

The use of cooled exhaust gas recirculation (EGR) is an essential feature of CI engines, as it delivers significant reduction of nitrogen oxide emissions [6]. One issue of EGR modules (i.e. recirculation valve and heat exchanger) is that over time their efficiency tends to degrade, mainly due to fouling phenomena [7-9]. In extreme cases, these can lead to plugging of gas passages, with condensation as the main driving mechanism [10].

Within this context, the ability to continuously monitor the performance of cooling effectiveness represents an important advantage that would ensure better performance throughout the lifetime of the product, as well as overall benefits with respect to fuel consumption and emissions. Usually this task is performed based on a 'virtual sensor' approach [11-14], meaning that information on the recirculated gas is acquired indirectly (e.g. based on recorded air flow, intake manifold temperature, pressure etc. and comparing the data with expected values for certain EGR valve lift settings). While straightforward and standardized, this approach is aimed at detecting failures and not at evaluating whether the module is operating at its rated flow and heat transfer parameters. This is mainly due to the fact that the measurement chain features relatively low accuracy and thus actual flow values can be determined with high error levels.

Therefore, the present study evaluated two different monitoring solutions, capable of online EGR module efficiency determinations. To this end, a CI engine was fitted with cooled exhaust gas recirculation and the operating characteristics were evaluated through gas and liquid flow, as well as temperature measurements. The validity and applicability of each monitoring solution was assessed and the most suitable setup was identified.

\section{Experimental setup and procedure}

The investigated EGR module is composed of a heat exchanger (shell and tube design) made of stainless steel and valve (poppet type, driven by an electric motor through a cam-roller mechanism) with its body in aluminum. It is generally fitted to a Diesel engine with a 3 cylinder inline configuration, displacement of 1.2 litres and $55 \mathrm{~kW}$ rated power. The actual valve component is also used for engines with maximum output up to $77 \mathrm{~kW}$.

*orresponding author: s.merola@im.cnr.it 
With these targets in mind, the experimental setup was organized so as to cover flow ranges as wide as possible.

An aspirated compression ignition engine was used for performing the trials; its main characteristics are listed in Table 1, and further details can be found in $[15,16]$. Apart from the straight forward correlation to the actual application of EGR modules, this setup was preferred with respect to a dedicated flow test bench. Even though the latter would have ensured more thorough and precise evaluation of heat transfer characteristics, the engine setup was chosen for conditions closer to real-world use, as well as the availability of input signals that are representative for the intended application in the field of automotive transportation.

Table 1. Engine characteristics.

\begin{tabular}{|c|c|}
\hline Operating cycle & 4 stroke, compression ignition \\
\hline Cylinders & 3 \\
\hline Bore x Stroke & $75.0 \mathrm{~mm} \mathrm{x} \mathrm{77.6} \mathrm{mm}$ \\
\hline Displacement & $1028 \mathrm{~cm}^{3}$ \\
\hline Compression ratio & $17.5: 1$ \\
\hline Rated power & $15 \mathrm{~kW} @ 3600 \mathrm{rpm}$ \\
\hline Rated torque & $60 \mathrm{Nm}$ @ 2000 rpm \\
\hline Fuel system & $\begin{array}{c}\text { direct injection, common rail, } \\
1400 \text { bar maximum pressure }\end{array}$ \\
\hline Air intake & naturally aspirated \\
\hline Intake valves opening & 13 deg bTDC \\
\hline Intake valves closing & 39 deg bTDC \\
\hline Exhaust valves opening & 38 deg bTDC \\
\hline Exhaust valves closing & 14 deg bTDC \\
\hline
\end{tabular}

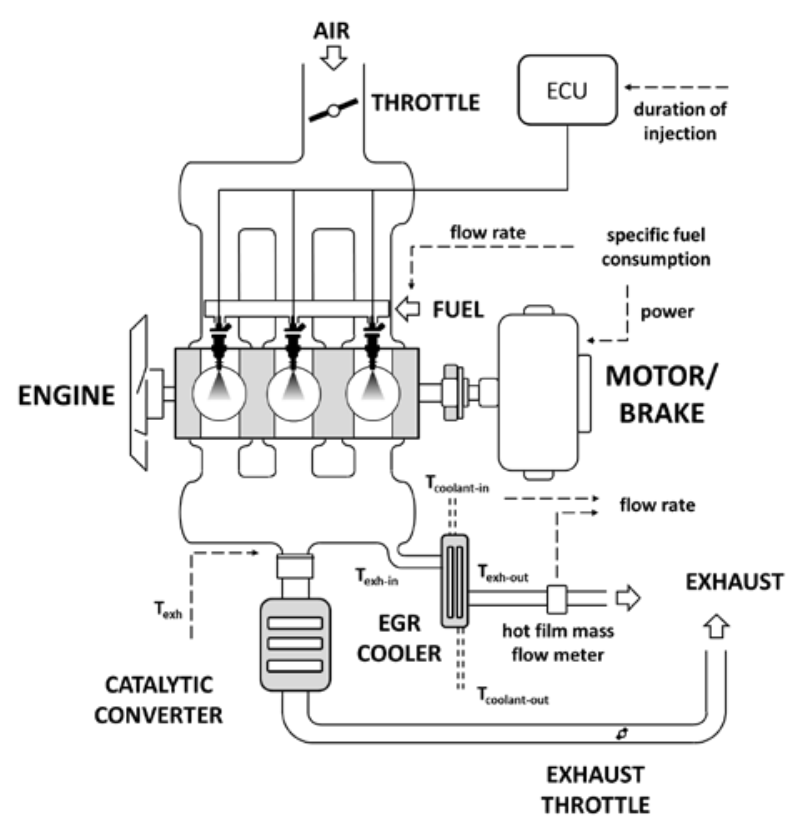

Fig. 1. Experimental setup in the initial measurement phase.

In a first phase of the evaluation, the EGR module was fitted at the exhaust of the engine (Figure 1), without any actual gas recirculation. This allowed a hot film mass flow meter to be used for measuring the entire flow of gas through the EGR valve (made possible by completely closing the exhaust throttle), without significantly interfering with engine operation. The setup also ensured redundant feedback of the actual flow, based on the readings of the engine's control unit flow meter. With this configuration, a wide range of exhaust gas flow could be investigated, as well a comprehensive interval of pressure drop upstream-downstream of the valve.

In the second stage, the gas outlet of the module was connected to the engine's intake manifold, thus providing conditions closer to real-world operation. Using the results of a GT-Power [17] model of the commercial engine that employs the investigated module, a 'most frequent' use range was defined, within the possibilities of operating the aspirated engine at acceptable combustion stability. In fact, it was found that the power unit featured an air flow of over $90 \mathrm{~kg} / \mathrm{h}$ at $3000 \mathrm{rpm}$; this value, combined with a limit of $30 \%$ recirculation, results in gas flow below $30 \mathrm{~kg} / \mathrm{h}$ through the valve-heat exchanger module. The generic EGR map used for simulations sets the highest rate of recirculation close to $40 \%$, at engine speeds around $1600 \mathrm{rpm}$ and low load, below 3 bar brake mean effective pressure (BMEP). In these conditions the air flow for the 1.2 litres engine is around $34 \mathrm{~kg} / \mathrm{h}$ and over $20 \mathrm{~kg} / \mathrm{h}$ exhaust gas flow into the intake manifold. Therefore, it was concluded that the setup in its second stage provided conditions that could be directly comparable to those encountered during realworld use of the EGR module.

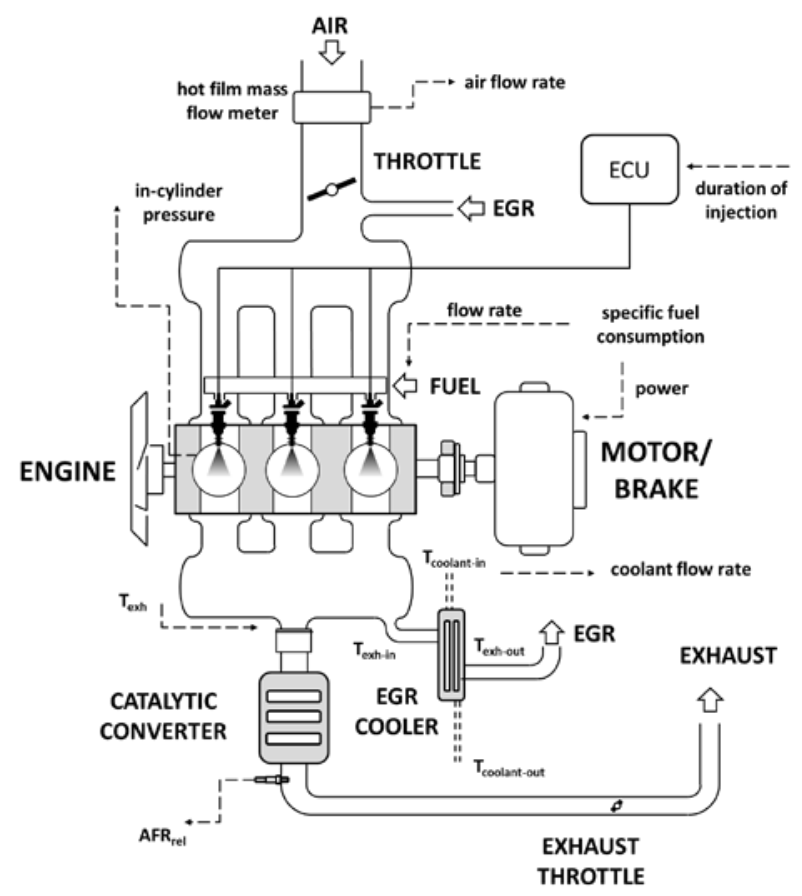

Fig. 2. Experimental setup in the second phase of measurements.

The main idea behind setting the operating conditions of the engine was to cover a wide range of recirculated exhaust gas flow, temperature and composition. For this reason, crankshaft rotational velocity was varied from 1000 to $3000 \mathrm{rpm}$, and relative air-fuel ratio was set in a range between 1.6 and 7.0. Engine output varied from 1 to $13 \mathrm{~kW}$ and resulting exhaust gas temperature was in a 
range from below $200{ }^{\circ} \mathrm{C}$ and up to maximum values close to $450{ }^{\circ} \mathrm{C}$. Backpressure was maintained at relatively low values, below $100 \mathrm{mbar}$, given that the aforementioned conditions of most frequent EGR use feature practically no boost. Of course, the power unit was allowed to reach rated coolant temperature during all trials; for each acquisition engine settings were kept constant, and the thermal regime of the EGR module was allowed to reach steady-state (i.e. data was recorded in a plateau-like region of the temperature curves).

Measurements related to the investigated module included gas and coolant flow values, and upstreamdownstream temperature determinations. Flow was evaluated with an accuracy of $\pm 3 \%$, by using an ultrasonic volumetric meter with full scale values up to 25 litres/min [18] for the liquid circuit and a hot film mass flow meter with readings up to $1000 \mathrm{~kg} / \mathrm{h}$ [19]. Temperature measurements were performed with $\mathrm{K}$ type thermocouples that featured an accuracy of $\pm 0.5{ }^{\circ} \mathrm{C}$ plus $0.2 \%$ of measured value. All these can be considered as state-of-the-art for automotive applications and are completely compatible with the accuracies that can be expected during real-world operation [20].

Two different parameters were calculated, i.e. effectiveness $\left(\eta_{\text {energy }}\right)$ and efficiency $\left(\eta_{\text {temp }}\right)$, by using eq. (1) and (2) respectively,

$$
\begin{gathered}
\eta_{\text {energy }}=\left[d m_{\text {gas }} \cdot c_{\text {pgas }} \cdot\left(T_{\text {gas-in }}-T_{\text {gas-out }}\right)\right] / \\
{\left[d m_{\text {liq }} \cdot c_{\text {liq }} \cdot\left(T_{\text {liq-out }}-T_{\text {liq-in }}\right)\right]} \\
\left.\eta_{\text {temp }}=\left(T_{\text {gas-in }}-T_{\text {gas-out }}\right) /\left(T_{\text {gas-in }}-T_{\text {liq-in }}\right)\right]
\end{gathered}
$$

where $d m_{\text {gas }} / d m_{\text {liq }}$ is the flow of gas/liquid through the module measured in $\mathrm{kg} / \mathrm{s}, c_{\text {pgas }} / c_{\text {liq }}$ specific heat of exhaust gas/coolant liquid at constant pressure in $\mathrm{J} / \mathrm{kg} \mathrm{K}$, $T_{\text {gas-in/out }} / T_{\text {liq-in/out }}$ gas/liquid temperatures measured in $\mathrm{K}$, upstream/downstream of the module. Of course, the first parameter (i.e. effectiveness, basically an expression of the first law of thermodynamics [21]) can provide much more information on the possible reasons of eventual changes observed in the performance of EGR modules. On the other hand, it requires flow measurements, which are much more difficult to implement. The second parameter (efficiency, calculated in a simplified version of the NTU method [22]) employed only temperature measurements.

\section{Results and discussion}

As mentioned in the previous section, different operative conditions were investigated, so as to cover a wide range of situations. Figures 3, 4 and 5 show results obtained in the second configuration (i.e. with actual exhaust gas recirculation).

At a fixed engine speed of $2500 \mathrm{rpm}$ (Figure 3), different EGR valve opening settings were scrutinized. Air-fuel ratio was close to constant, thus ensuring a narrow exhaust gas temperature range around $250{ }^{\circ} \mathrm{C}$. Efficiency values showed a decreasing trend as the valve was opened. On the contrary, effectiveness featured a non-monotonous variation. The increasing trend of this parameter up to around $8 \mathrm{~kg} / \mathrm{h}$ can be attributed to the relatively low flow values, a range in which reduced accuracy of the flow meter can be expected. This also resulted in a wide spread of results, as it will become more evident later on; it should be noted that there was even a point with a calculated effectiveness of 1.06, and several over 0.99 , very unlikely even if possible.

Nonetheless, the fact that efficiency values were very close to unity suggests that other heat losses also played a significant role. Indeed, one possible reason is that gas flow past the valve when it was near complete closure resulted in increased convective heat transfer in that region. Dissipation of heat from the EGR module to the ambient via radiation could also explain why only part of the heat flux from the exhaust gas stream was transferred to the liquid coolant. Condensation within the heat exchanger is another possible explanation. This phenomenon should exert a more significant influence at high flow rates, but even at low values it cannot be excluded.

Both parameters showed a decreasing trend at flow ratings over $8 \mathrm{~kg} / \mathrm{h}$, suggesting a significant effect of the actual quantity of gas passing through the module.

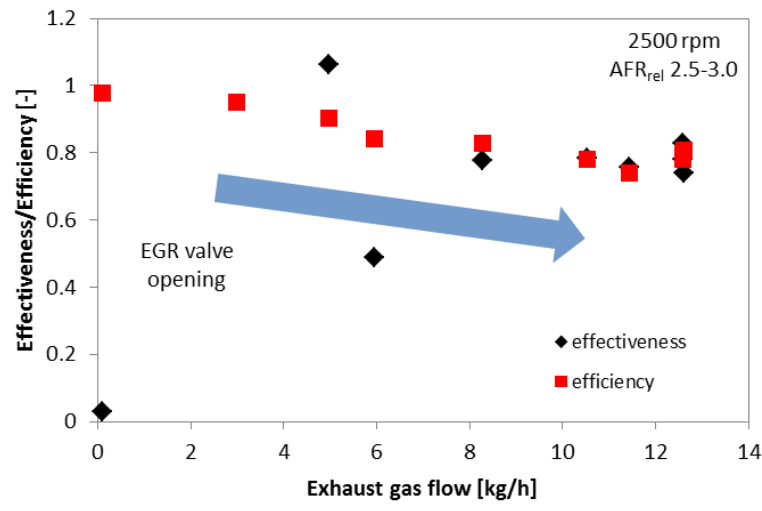

Fig. 3. Effectiveness and efficiency values at increasing valve opening.

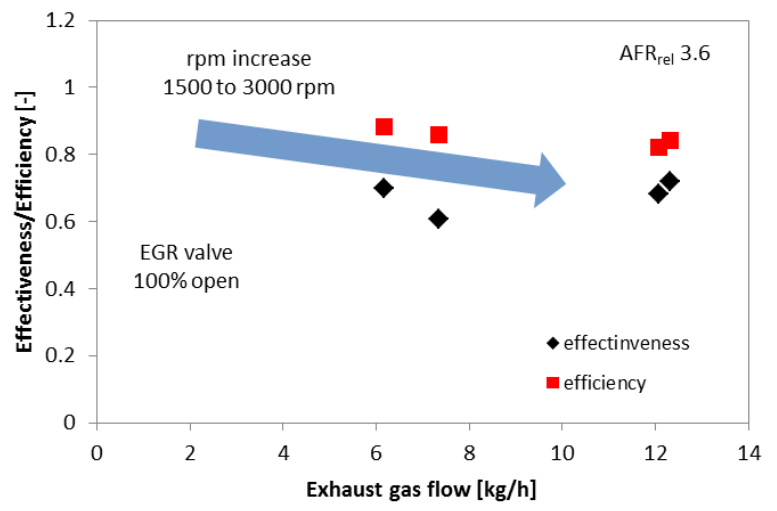

Fig. 4. Effect of increasing engine speed.

Variations in engine speed (Figure 4) seemed to play only a minor role, and showed reduced influence on effectiveness/efficiency. As expected, higher rotational velocity featured increased gas temperature (up to around $200{ }^{\circ} \mathrm{C}$, for the relatively high air-fuel ratio), 
while the opposite was true for the other end of the range (e.g. around $150{ }^{\circ} \mathrm{C}$ was recorded for $1500 \mathrm{rpm}$ ). Again, the wider spread of data for the effectiveness parameter can be attributed to relatively low accuracy gas flow measurements below values of $8 \mathrm{~kg} / \mathrm{h}$.

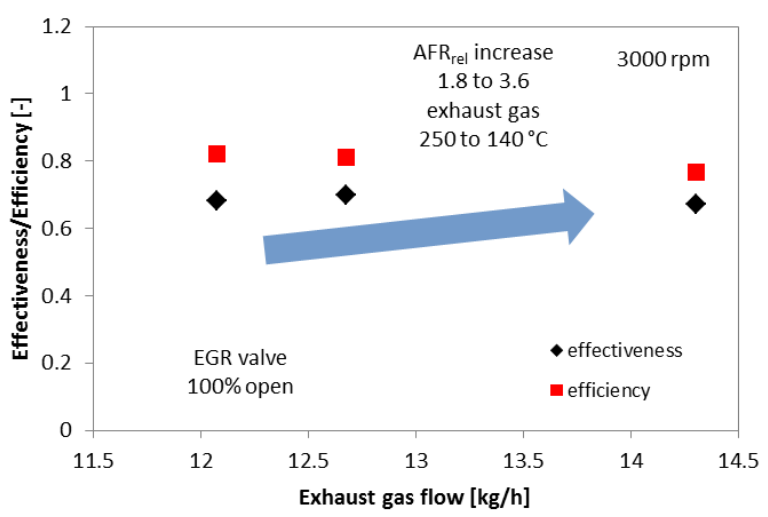

Fig. 5. Effectiveness and efficiency for various relative air-fuel ratios.

Finally, the effect of varying air-fuel ratio was also found to play a minor role, meaning that both parameters showed contained changes at different lambda values (Figure 5). This also seems to confirm that the actual gas flow value exerts the most important influence.

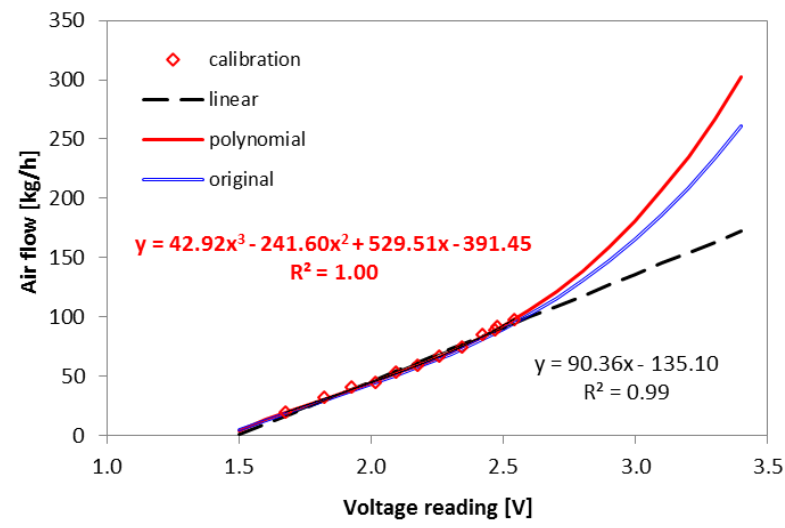

Fig. 6. Calibrated voltage-flow curve for the hot film mass flow meter.

To provide more insight into the effect that flow measurements has on the results, a brief discussion is warranted with respect to the device that was used. Figure 6 shows the calibration results for the hot film flow meter, performed with a device that featured an accuracy of $\pm 1 \%$. Even if a simple linear correlation would have ensured accurate data within the range of interest ( $\mathrm{R}^{2}$ over 0.9900 ), a polynomial fit (with an $\mathrm{R}^{2}$ value of 0.9989) was preferred for improved precision (solid line labeled as 'polynomial'). The calibrated curve closely follows that provided by the manufacturer (double line labeled as 'original', characteristic curve ranging from 15 to $850 \mathrm{~kg} / \mathrm{h}$ for voltage readings from 1.34 to $4.57 \mathrm{~V}$ ), with an offset of $-20 \mathrm{~kg} / \mathrm{h}$. This renders the flow meter usable in the investigated flow range, with the value of $1.46 \mathrm{~V}$ as the lowest useful voltage; it also explains the relatively high dispersion of effectiveness values for gas flow below $5 \mathrm{~kg} / \mathrm{h}$. Nonetheless, the fact that effectiveness/efficiency results are comparable, can be considered as further confirmation that flow measurements were valid in the $10-20 \mathrm{~kg} / \mathrm{h}$ range, characteristic for 'most frequent' use in real-world situations.

One of the main conclusions that can be drawn is that both methods of evaluation delivered completely comparable results within the flow range most frequently employed for the commercial engine. This is confirmed by the points shown in Figure 7, that features all the operative conditions, without distinguishing features. Another evident conclusion is that the actual flow value plays the major role in how efficient the module is at cooling gas. As expected [9], effectiveness/efficiency values were around $80 \%$ in a relatively wide flow range; both parameters showed a decreasing trend as flow through the valve was increased.

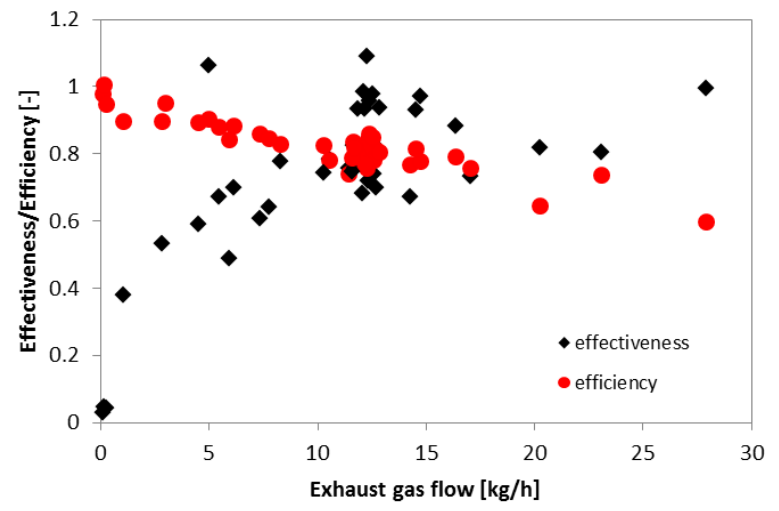

Fig. 7. Efficiency evaluations with the two categories of measurements.

An important observation is that calculated effectiveness values featured wider spread compared to efficiency. This is directly related to the gas flow values, given that the measurement device featured relatively low accuracy at the lower end of the range. Together with higher complexity of measurement requirements, the results of the method based on effectiveness render it less favorable for the intended goal of online monitoring. Efficiency calculations represent a much more convenient route, with addition of two measurement points. Basically, integration entails only temperature evaluations upstream/downstream of the gas line, thus resulting in reduced footprint of the setup. Given that only one liquid temperature value is required, the measurement already implemented on vehicles (i.e. coolant temperature signal) can be taken as reference, and therefore bringing additional reduction of cost.

\section{Conclusion}

An experimental investigation was performed for evaluating the applicability of online monitoring solutions aimed at determining the efficiency of EGR modules in automotive applications. The main idea was 
to identify possible parameters to acquire, and integrate the data provided by the new sensor with existing 'virtual sensing' components already implemented on the vehicle. Two different procedures were applied, one for determining effectiveness (based on flow and temperature measurements) and the second for calculating efficiency (by using temperature values only).

One of the main conclusions was that both evaluation procedures delivered comparable results within the useful flow range. The calculated values of around $80 \%$ for the two parameters were also in line with data found in the literature. As a major conclusion, measuring gas temperatures upstream and downstream of the EGR module was identified as the route most suited for monitoring its efficiency online. Reduced complexity of the measurement devices and easier integration of the recorded data into the vehicles' communication network, renders the identified solution the most promising route for developing an EGR efficiency sensor capable of continuous evaluation.

This work was financially supported within the VEDO project by the European Union and Campania Region of Italy, through the POR Campania FESR (European Regional Development Fund, original title in Italian) 2014-2020 program. The contribution of Carlo Rossi and Bruno Sgammato in the experimental activities is also gratefully acknowledged.

\section{References}

1. G. Kalghatgi, Appl. Energ. 225, 965-974 (2018), doi: 10.1016/j.apenergy.2018.05.076.

2. K. Morganti, M. Al-Abdullah, A. Alzubail, G. Kalghatgi, Y. Viollet, R. Head, A. Khan, A. AbdulManan, Appl. Energ. 208, 1538-1561 (2017), doi:10.1016/j.apenergy.2017.08.213.

3. C.D. Rakopoulos, D.C. Rakopoulos, G.M., Kosmadakis, R.G., Papagiannakis, Energy 174, 1145-1157 (2019), doi: 10.1016/j.energy.2019.03.063

4. J. Benajes, A. García, J. Monsalve-Serrano, S. Martínez-Boggio, Appl. Therm. Eng. 164, 114430 (2020), doi: 10.1016/j.applthermaleng.2019.114430

5. M. Parravicini, C. Barro, K. Boulouchos, Fuel 259,116166 (2020), doi: 10.1016/j.fuel.2019.116166
6. V. Macián, V. Bermúdez, D. Villalta, L. Soto, Appl. Therm. Eng. 163, 114245 (2019), doi: 10.1016/j.applthermaleng.2019.114245

7. R. Zhan, S. Eakle, J. Miller, J. Anthony, SAE Int. J. Engines 1, 59-64 (2009), doi: 10.4271/2008-010066

8. J. Hoard, M. Abarham, D., Styles, J., Giuliano, et al., SAE Int. J. Engines 1, 1234-1250 (2009), doi: 10.4271/2008-01-2475

9. J. Lee, K, Min, J. Mech. Sci. Technol. 28, 33953401 (2014), doi: 10.1007/s12206-014-0752-8

10. C. Sluder, J. Storey, M. Lance, SAE Technical Paper 2014-01-0640 (2014), doi: 10.4271/2014-010640

11. D. Pachner, J. Beran, J. Tigelaar, SAE Technical Paper 2016-01-0096 (2016), doi:10.4271/2016-010096

12. S. Lee, Y. Lee, K. Han, K. Lee, et al., SAE Technical Paper 2016-01-0561 (2016), doi: 10.4271/2016-01-0561

13. D. Pachner, J. Beran, SAE Technical Paper 201601-1064 (2016), doi: 10.4271/2016-01-1064

14. S. Tsironas, O. Stenlaas, M. Apell, A. Cronhjort, SAE Technical Paper 2019-01-1170 (2019), doi: 10.4271/2019-01-1170

15. A. Magno, E. Mancaruso, B.M. Vaglieco, Fuel 106, 618-630 (2016), doi: 10.1016/j.energy.2016.03.106

16. S. Di Iorio, A. Magno, E. Mancaruso, B.M. Vaglieco, Fuel Proc. Technol. 159, 200-210 (2017), doi: 10.1016/j.fuproc.2017.01.009

17. *** Gamma Technologies, GT-SUITE Flow Theory Manual Version 7.4 (2013)

18. *** Cynergy ${ }^{3}$ Components Ultrasonic Flow Meter UF25B, Technical data (2018)

19. *** Bosch Hot-film air-mass meter, Type HFM 5 Technical data (2012)

20. J.B. Heywood, Internal Combustion Engine Fundamentals, (New York: McGraw Hill, 1988)

21. Y.A. Cengel, Heat Transfer, A practical Approach, $2^{\text {nd }}$ edition, Chapter 13, (New York, McGraw Hill, 2003)

22. F.P. Incropera, D.P. Dewitt, T.L. Bergman, A.S. Lavine, Fundamentals of heat and mass transfer, $6^{\text {th }}$ edition, Chapter 11, (John Wiley \& Sons, 2007) 